\title{
PERCEPCIÓN, TIPOS Y MEDIDAS DE CONTROL DE LA CORRUPCIÓN, SEGÚN EL SEXO, CICLO ACADÉMICO Y LA FACULTAD A LA QUE PERTENECEN LOS ESTUDIANTES UNIVERSITARIOS
}

\author{
Luis Vicuña P. ${ }^{1}$, Héctor Hernández V. ${ }^{2}$, Mildred Paredes T. ${ }^{3}$, José C. Rivera B. ${ }^{4}$, José Rios D., \\ Christian Santillana P., Jenny Torres M.
}

(Recibido el 13/11/ 2006, aceptado el 04/12/2006)

\begin{abstract}
RESUMEN
El presente estudio trata de la forma como el universitario conceptúa a la corrupción, identifica actos corruptos dentro de su facultad y proponen soluciones, en función al sexo, ciclo y facultad académica a la que pertenecen. La muestra fue de 931 representativa al 0,03 de margen de error, distribuidos por facultades académicas. La muestra seleccionada aleatoriamente contestó a un cuestionario de tres preguntas, previamente validadas semánticamente; luego en grupos no mayores de diez estudiantes se conversó acerca de sus respuesta con el objeto de conocer la confiabilidad de las mismas, encontrando una correlación del 0,90 entre las opiniones profundizadas en la sesión dinámica con sus respuestas escritas en el cuestionario.
\end{abstract}

Sobresalen resultados, respecto a la conceptualización de la corrupción: el $8 \%$ dicen que es transgresión de normas, $11 \%$ abuso de autoridad, $15 \%$ como un delito, para el $9 \%$ es una enfermedad, para el $37 \%$ benefico personal.

Entre los actos corruptos percibidos atribuyen al abuso de poder de la burocracia el $33 \%$, $9 \%$ a enriquecimiento ilícito y a alumnos que pagan coimas respectivamente, $8 \%$ abuso de poder del docente.

En las soluciones para controlar la corrupción proponen: el 19\% educación en valores, $13 \%$ fiscalizando, $8 \%$ transparencia, cambio de sistema, cambio individual y concientización, respectivamente, $7 \%$ aplicación de medidas restrictivas. Estos datos no difieren en función al sexo ni al ciclo ni a la facultad académica a la que pertenecen.

Palabras clave: Corrupción, atribución, conceptos de corrupción, tipos de corrupción, soluciones a la corrupción.

\footnotetext{
Docente Principal, Facultad de Psicología de la UNMSM. E-mail: Ivicunap@unmsm.edu.pe

Docente Asociado de la Facultad de Psicología de la UNMSM. E-mail: hhernadezv@unmsm.edu.pe

3 Docente Asociado de la Facultad de Psicología de la UNMSM. E-mail: mparedest@unmsm.edu.pe

4 Docente Asociado de la Facultad de Psicología de la UNMSM. E-mail: jriverab@unmsm.edu.pe
} 


\begin{abstract}
The present study deals with the form like the college student they conceptuan to the corruption, identifies corrupt acts within its faculty and propose solutions, in function to sex, cycle and academic faculty to which they belong. The sample was of 931 representative to the 0,03 of error margin, distributed by academic faculties. The selected sample randomly, answered a questionnaire of three questions, previously validated semantically; soon in greater groups of ten students it was not talked about his answer with the intention of knowing the trustworthiness the same ones, finding a correlation of the 0,90 between the opinions deepened in the dynamic session with his answers written in the questionnaire.
\end{abstract}

They excel results, with respect to the concept of the corruption: $8 \%$ say that it is transgression of norms, to $11 \%$ abuse of office, $15 \%$ like a crime, for $9 \%$ is a disease, for $37 \%$ beneficial personnel.

Between the perceived corrupt acts they attribute to the abuse authority of the bureaucracy $33 \%, 9 \%$ to illicit enrichment and students who pay briberies respectively, $8 \%$ abuse authority of the educational one.

In the solutions to control the corruption they propose: $19 \%$ education in values, $13 \%$ controlling, $8 \%$ transparency, change of system, individual change and awareness, respectively, $7 \%$ application of restrictive measures. These data differ in function to sex neither to the cycle nor to the academic faculty to which they belong.

Keywords: Corruption, attribution, concepts of corruption, types of corruption, solutions to the corruption.

\title{
INTRODUCCIÓN
}

Luis Vicuña Peri et al. (2003) estudiaron las disposiciones psicológicas hacia la corrupción desde el enfoque de los estilos atribucionales, encontrando que el estilo atribucional predominante se caracteriza por el mayor índice de Externalidad acompañado de inestabilidad y la especificidad definiendo que el estilo explicativo hacia la corrupción en un $73 \%$ en la muestra estudiada, son de estilo explicativo optimista. Lo que significa que las disposiciones psicológicas hacia la corrupción solo en un $27 \%$ de púberes, adolescentes y jóvenes no tendrían visos de solución, donde la desesperanza asociado a la depresión serian los trastornos a esperarse en este grupo.

Las representaciones sociales de la corrupción, democrática y ciudadanía (2003) concluye que un $42 \%$ de los entrevistados de Lima, Chiclayo, Huanuco, Huancavelica y Pucallpa, pueden ser corruptos si se les presenta la oportunidad. Además de todas las instituciones del poder en el Perú, los estudiantes confían más en la Iglesia y desconfían del poder Ejecutivo.

Por su parte Velásquez Centeno Carlos (2003), en su estudio sobre valores en estudiantes con y sin participación en actos violentos, concluye que se encuentra mayor desarrollo de los valores en el Callao y en el cercado de Lima, mientras que la pérdida más frecuente de éstas se da en los conos este, sur y norte debido a la pluralidad y al centralismo, que genera un clima de desconfianza en las relaciones interpersonales.

Por otra parte en la Universidad de Concepción de Chile (1999) concluyen que los estudiantes universitarios, en un $92 \%$, consideran que la corrupción está relacionada con la apropiación ilegítima de dinero, el $85 \%$ considera a las influencias para lograr beneficios personales, un $20 \%$ en ámbitos privados en práctica como lavado de dinero y tráfico de influencias. 
Johnston citado por García et al. (1999) asume que la corrupción es el abuso de un cargo, del poder y de los recursos públicos para la obtención de beneficios personales. El hecho de que los conceptos «de contexto histórico social» y sistema de valores resulten factores cambiantes, al igual que los conceptos de «abuso», «público y privado» y de «beneficio», hace que la mejor forma de contextualizar e indicar lo que se entiende como corrupción es a través de las referencias hechas en todo tipo de reglamento formal, que, para el caso de una nación, sería el código penal.

Algunos autores señalan que el interés público es una idea vaga y que las leyes formales, en muchas ocasiones, poseen escasa legitimidad; este criterio toma como referente a la opinión pública o a las normas culturales para evaluar la existencia de un fenómeno de corrupción, la opinión pública o las normas culturales varían no solo según las diversas culturas, sino también según el segmento de la sociedad. Son de criterio moral y la opinión de una época dentro de un contexto dado las que determinan que un acto cualquiera, que implica el «perjuicio de un beneficio publico para satisfacer uno privado, será considerado corrupto».

Otro enfoque para definir a la corrupción es el de Heidenheimer (1999), quien ha diferenciado matices de corrupción según las percepciones éticas de la clase política y la opinión pública. Se llama «corrupción negra» a aquellas acciones más potentes y universalmente aceptadas como el soborno la extorsión. La llamada «corrupción blanca» ocurre en el caso en que actos corruptos son aceptados ampliamente. Entre la corrupción negra y blanca se encuentra la «corrupción gris», en la que se incluyen todas las conductas acerca de las cuales las élites y la opinión pública discrepan al momento de evaluarlas como corruptas.

Una definición integrativa de las características de corrupción es la entregada por FernándezDols (1993), la fórmula Corrupción = monopolio + discrecionalidad - transparencia de Cartier-Bresson (1996, en García et al., 1999), así como la agrupación y clasificación de tipos de corrupción puede verse en Vicuña L. et al., 2004. En el presente sólo a manera didáctica presentamos la clasificación de los actos corruptos en 16 categorías, las cuales a su vez, pueden ser agrupadas en tres grupos que se detallan a continuación; para analizar los modelos que la sustentan remítase a Vicuña L. et al., 2004.

1. Corrupción directa. Es aquella corrupción en que ocurre un aprovechamiento directo de su función, por parte del funcionario público, el privado o el individuo particular, para obtener un beneficio.

2. Corrupción mediada. En estas acciones el beneficio particular proviene de un tercero.

3. Aprovechamiento de procedimientos. En este grupo de categorías el acto corrupto consistiría en el aprovechamiento de falencias en el sistema de procedimientos en que se halla inserto el individuo.

\section{Abuso de poder}

Apropiación de bienes privados o públicos

El enriquecimiento ilícito

La extorsión

El favoritismo y el nepotismo

La aceptación de ventajas indebidas

El tráfico de influencia

El soborno

El clientismo político

Las malas prácticas electorales

El manejo indebido de bienes o fondos públicos y/o privados

El manejo indebido y el ocultamiento de información

La negociación incompatible

Los manejos indebidos de los procedimientos

públicos

El lavado de dinero

Nepotismo 
Otra forma de entender el fenómeno de la corrupción es considerarlo tanto como un recurso y como un proceder. En la primera visión, la corrupción referida como un recurso expeditivo, la corrupción se utiliza para acelerar los procesos y, por tanto, el corrupto es «un experto en atajos». Esta característica racional por excelencia sustrae al corrupto del orden de la inadvertencia, siendo jamás inocente, pues siempre sabe lo que hace, está sujeto a la vigilia cognitiva, al darse cuenta.

Desde la segunda perspectiva, la corrupción es un proceder, un modo de hacer para obtener beneficios. Este proceder tiene una característica sustancial, que es la desviación respecto de una cierta normatividad, o sea, la obtención del beneficio, se lleva a cabo, al margen de la conducta normal. La desviación puede hacerse respecto a una norma jurídica o normas éticas (Silva y Hernández, 1995).

De las definiciones se desprenden las siguientes características del acto corrupto:

1. Toda acción corrupta consiste en la trasgresión de una norma.

2. Se realiza para la obtención de un beneficio privado.

3. Surge dentro del ejercicio de una función asignada.

4. El individuo corrupto intenta siempre encubrir activamente su comportamiento.

La corrupción se traduciría, por una parte, en la aparición de fuentes de poder alternativas, capaces de manipular la situación a favor del individuo que transgrede la norma e imponer otra norma alternativa en propio beneficio y, por otra parte, a una mayor tolerancia de la opinión pública frente a este tipo de acciones ilícitas.

Estadísticas de la corrupción, actualmente con indicadores que se aproximan a ser confiables según Transparencia Internacional (TI) es una organización no gubernamental podemos conocer la posición de los países en función a los indicadores de corrupción. Esta organización entrega cada año el más completo índice de percepción de la corrupción en el mundo.

El Índice de Percepción de la Corrupción (IPdC) es una «encuesta de encuestas», basada en numerosas encuestas con expertos y público en general acerca de sus puntos de vista sobre la extensión de la corrupción en muchos países alrededor del mundo, y busca ser un incentivo para los gobiernos de los distintos países para que luchen contra la corrupción.

El IPdC de Transparencia Internacional correspondiente a 1998 cubre 85 países, siendo percibidos como los menos corruptos aquellos que alcanzan puntuaciones cercanas a 10 .

A pesar de que el IPdC cubre un número récord de más de 80 países, son muchos los países que no han sido incluidos en el índice, debido a que no se dispone de suficientes datos confiables. El IPdC muestra que la corrupción no es percibida como una plaga exclusiva de los países en desarrollo. Muchos en Europa Central y Oriental también la presentan, ver Vicuña L. et al., 2004.

El IPdC anual sensibiliza a la opinión pública en todo el mundo sobre la cuestión de la corrupción y constituye un factor de peso en las decisiones de inversión en el extranjero de las corporaciones multinacionales.

El puntaje del IPdC de 1998 se refiere a las percepciones del grado de corrupción, como es visto por los empresarios, analistas de riesgo y público en general, en una escala entre 10 (sumamente íntegro) y 0 (sumamente corrupto). 
En el mencionado año, el Perú se encontraba cerca de la mediana, ya que de los datos de 85 países, el nuestro fue ubicado en el puesto número 41, con un índice de percepción de corrupción igual a 4,5.

En el presente año la tabla del IPdC de Transparencia Internacional 2006, usando los datos de 163 países, el Perú se encuentra en el puesto 76, ubicándose por debajo de la mediana con un IPdC igual a 3,3 juntamente con Brasil, mundialmente hemos disminuido nuestra integridad aún cuando en Latinoamérica ocupamos el cuarto puesto de integridad; entre los más corruptos se encuentran Venezuela $(2,3)$ y Ecuador $(2,3)$, mientras que en el otro extremo están Chile $(7,3)$ y Uruguay $(6,4)$, ver la siguiente tabla sin número.

\section{Índice de Percepción de la Corrupción Transparency International 2006}

\begin{tabular}{|c|c|c|c|c|}
\hline $\begin{array}{c}\text { Rango del } \\
\text { país }\end{array}$ & País/Territorio & $\begin{array}{l}\text { Puntuación del } \\
\text { IPC 2006* }\end{array}$ & $\begin{array}{c}\text { Rango de } \\
\text { confiabilidad } * *\end{array}$ & $\begin{array}{c}\text { Encuestas } \\
\text { utilizadas*** }\end{array}$ \\
\hline \multirow{3}{*}{1} & Finlandia & 9,6 & 9,4 - 9,7 & 7 \\
\hline & Islandia & 9,6 & $9,5-9,7$ & 6 \\
\hline & Nueva Zelanda & 9,6 & $9,4-9,6$ & 7 \\
\hline 4 & Dinamarca & 9,5 & $9,4-9,6$ & 7 \\
\hline 5 & Singapur & 9,4 & $9,2-9,5$ & 9 \\
\hline 6 & Suecia & 9,2 & $9,0-9,3$ & 7 \\
\hline 7 & Suiza & 9,1 & $8,9-9,2$ & 7 \\
\hline 8 & Noruega & 8,8 & $8,4-9,1$ & 7 \\
\hline \multirow{2}{*}{9} & Australia & 8,7 & $8,3-9,0$ & 8 \\
\hline & Holanda & 8,7 & 8,3 - 9,0 & 7 \\
\hline \multirow{3}{*}{11} & Austria & 8,6 & $8,2-8,9$ & 7 \\
\hline & Luxemburgo & 8,6 & $8,1-9,0$ & 6 \\
\hline & Reino Unido & 8,6 & $8,2-8,9$ & 7 \\
\hline 14 & Canadá & 8,5 & $8,0-8,9$ & 7 \\
\hline 15 & Hong Kong & 8,3 & $7,7-8,8$ & 9 \\
\hline 16 & Alemania & 8,0 & $7,8-8,4$ & 7 \\
\hline 17 & Japón & 7,6 & $7,0-8,1$ & 9 \\
\hline \multirow{2}{*}{18} & Francia & 7,4 & $6,7-7,8$ & 7 \\
\hline & Irlanda & 7,4 & $6,7-7,9$ & 7 \\
\hline \multirow{3}{*}{20} & Bélgica & 7,3 & $6,6-7,9$ & 7 \\
\hline & Chile & 7,3 & $6,6-7,6$ & 7 \\
\hline & Estados Unidos & 7,3 & $6,6-7,8$ & 8 \\
\hline 23 & España & 6,8 & $6,3-7,2$ & 7 \\
\hline \multirow{2}{*}{24} & Barbados & 6,7 & $6,0-7,2$ & 4 \\
\hline & Estonia & 6,7 & $6,1-7,4$ & 8 \\
\hline \multirow{2}{*}{26} & Macao & 6,6 & $5,4-7,1$ & 3 \\
\hline & Portugal & 6,6 & $5,9-7,3$ & 7 \\
\hline \multirow{3}{*}{28} & Malta & 6,4 & $5,4-7,3$ & 4 \\
\hline & Eslovenia & 6,4 & $5,7-7,0$ & 8 \\
\hline & Uruguay & 6,4 & $5,9-7,0$ & 5 \\
\hline 31 & Emiratos Árabes Unidos & 6,2 & 5,6 - 6,9 & 5 \\
\hline \multirow{2}{*}{32} & Bután & 6,0 & $4,1-7,3$ & 3 \\
\hline & Qatar & 6,0 & $5,6-6,5$ & 5 \\
\hline \multirow{2}{*}{34} & Israel & 5,9 & $5,2-6,5$ & 7 \\
\hline & Taiwán & 5,9 & $5,6-6,2$ & 9 \\
\hline 36 & Bahréin & 5,7 & $5,3-6,2$ & 5 \\
\hline \multirow{2}{*}{37} & Botsuana & 5,6 & $4,8-6,6$ & 6 \\
\hline & Chipre & 5,6 & $5,2-5,9$ & 4 \\
\hline 39 & Omán & 5,4 & $4,1-6,2$ & 3 \\
\hline 40 & Jordania & 5,3 & $4,5-5,7$ & 7 \\
\hline 41 & Hungría & 5,2 & $5,0-5,4$ & 8 \\
\hline
\end{tabular}


PERCEPCIÓN, TIPOS Y MEDIDAS DE CONTROL DE LA CORRUPCIÓN

\begin{tabular}{|c|c|c|c|c|}
\hline \multirow{2}{*}{42} & Mauricio & 5,1 & $4,1-6,3$ & 5 \\
\hline & Corea del Sur & 5,1 & $4,7-5,5$ & 9 \\
\hline 44 & Malasia & 5,0 & $4,5-5,5$ & 9 \\
\hline \multirow[t]{2}{*}{45} & Italia & 4,9 & $4,4-5,4$ & 7 \\
\hline & República Checa & $\overline{4,8}$ & $4,4-5,2$ & 8 \\
\hline \multirow[t]{2}{*}{46} & Kuwait & 4,8 & $4,0-5,4$ & 5 \\
\hline & Lituania & 4,8 & $4,2-5,6$ & 6 \\
\hline \multirow{2}{*}{49} & Letonia & 4,7 & $4,0-5,5$ & 6 \\
\hline & Eslovaquia & 4,7 & $4,3-5,2$ & 8 \\
\hline \multirow{2}{*}{51} & Suráfrica & 4,6 & $4,1-5,1$ & 8 \\
\hline & Túnez & 4,6 & $3,9-5,6$ & 5 \\
\hline 53 & Dominica & 4,5 & $3,5-5,3$ & 3 \\
\hline 54 & Grecia & 4,4 & $3,9-5,0$ & 7 \\
\hline \multirow{2}{*}{55} & Costa Rica & $\overline{4,1}$ & $3,3-4,8$ & 5 \\
\hline & Namibia & 4,1 & $3,6-4,9$ & 6 \\
\hline \multirow{2}{*}{57} & Bulgaria & 4,0 & $3,4-4,8$ & 7 \\
\hline & El Salvador & 4,0 & $3,2-4,8$ & 5 \\
\hline 59 & Colombia & 3,9 & $3,5-4,7$ & 7 \\
\hline 60 & Turquía & 3,8 & $3,3-4,2$ & 7 \\
\hline \multirow{2}{*}{61} & Jamaica & 3,7 & $3,4-4,0$ & 5 \\
\hline & Polonia & 3,7 & $3,2-4,4$ & 8 \\
\hline \multirow{3}{*}{63} & Líbano & 3,6 & $3,2-3,8$ & 3 \\
\hline & Seychelles & 3,6 & $3,2-3,8$ & 3 \\
\hline & Tailandia & 3,6 & $3,2-3,9$ & 9 \\
\hline \multirow{3}{*}{66} & Belice & 3,5 & $2,3-4,0$ & 3 \\
\hline & Cuba & 3,5 & $1,8-4,7$ & 3 \\
\hline & Granada & 3,5 & $2,3-4,1$ & 3 \\
\hline 69 & Croacia & 3,4 & $3,1-3,7$ & 7 \\
\hline \multirow{9}{*}{70} & Brasil & 3,3 & $3,1-3,6$ & 7 \\
\hline & China & 3,3 & $3,0-3,6$ & 9 \\
\hline & Egipto & 3,3 & $3,0-3,7$ & 6 \\
\hline & Ghana & 3,3 & $3,0-3,6$ & 6 \\
\hline & India & 3,3 & $3,1-3,6$ & 10 \\
\hline & México & 3,3 & $3,1-3,4$ & 7 \\
\hline & Perú & 3,3 & $2,8-3,8$ & 5 \\
\hline & Arabia Saudita & 3,3 & $2,2-3,7$ & 3 \\
\hline & Senegal & 3,3 & $2,8-3,7$ & 5 \\
\hline \multirow{5}{*}{79} & Burkina Faso & 3,2 & $2,8-3,6$ & 5 \\
\hline & Lesotho & 3,2 & $2,9-3,6$ & 5 \\
\hline & Moldavia & 3,2 & $2,7-3,8$ & 7 \\
\hline & Marruecos & 3,2 & $2,8-3,5$ & 6 \\
\hline & Trinidad y Tobago & 3,2 & $2,8-3,6$ & 5 \\
\hline \multirow{6}{*}{84} & Algeria & 3,1 & $2,7-3,6$ & 5 \\
\hline & Madagascar & 3,1 & $2,3-3,7$ & 5 \\
\hline & Mauritania & 3,1 & $2,1-3,7$ & 4 \\
\hline & Panamá & 3,1 & $2,8-3,3$ & 5 \\
\hline & Rumanía & 3,1 & $3,0-3,2$ & 8 \\
\hline & Sri Lanka & 3,1 & $2,7-3,5$ & 6 \\
\hline \multirow{3}{*}{90} & Gabón & 3,0 & $2,4-3,3$ & 4 \\
\hline & Serbia & 3,0 & $2,7-3,3$ & 7 \\
\hline & Surinam & $\mathbf{3 , 0}$ & $2,7-3,3$ & 4 \\
\hline \multirow{6}{*}{93} & Argentina & 2,9 & $2,7-3,2$ & 7 \\
\hline & Armenia & 2,9 & $2,7-3,0$ & 6 \\
\hline & Bosnia y Herzegovina & 2,9 & $2,7-3,1$ & 6 \\
\hline & Eritrea & 2,9 & $2,2-3,5$ & 3 \\
\hline & Siria & 2,9 & $2,3-3,2$ & 3 \\
\hline & Tanzania & 2,9 & $2,7-3,1$ & 7 \\
\hline & República Dominicana & 2,8 & $2,4-3,2$ & 5 \\
\hline & Georgia & 2,8 & $2,5-3,0$ & 6 \\
\hline & Mali & 2,8 & $2,5-3,3$ & 7 \\
\hline 99 & Mongolia & 2,8 & $2,3-3,4$ & 5 \\
\hline & Mozambique & 2,8 & $2,5-3,0$ & 7 \\
\hline & Ucrania & 2,8 & $2,5-3,0$ & 6 \\
\hline
\end{tabular}


LUIS VICUÑA P. ET AL.

\begin{tabular}{|c|c|c|c|c|}
\hline \multirow{6}{*}{105} & Bolivia & 2,7 & $2,4-3,0$ & 6 \\
\hline & Irán & 2,7 & $2,3-3,1$ & 3 \\
\hline & Libia & 2,7 & $2,4-3,2$ & 3 \\
\hline & Macedonia & 2,7 & $2,6-2,9$ & 6 \\
\hline & Malawi & 2,7 & $2,5-3,0$ & 7 \\
\hline & Uganda & 2,7 & $2,4-3,0$ & 7 \\
\hline \multirow{10}{*}{111} & Albania & 2,6 & $2,4-2,7$ & 5 \\
\hline & Guatemala & 2,6 & $2,3-3,0$ & 5 \\
\hline & Kazajstán & 2,6 & $2,3-2,8$ & 6 \\
\hline & Laos & 2,6 & $2,0-3,1$ & 4 \\
\hline & Nicaragua & 2,6 & $2,4-2,9$ & 6 \\
\hline & Paraguay & 2,6 & $2,2-3,3$ & 5 \\
\hline & Timor Oriental & 2,6 & $2,3-3,0$ & 3 \\
\hline & Vietnam & 2,6 & $2,4-2,9$ & 8 \\
\hline & Yemen & 2,6 & $2,4-2,7$ & 4 \\
\hline & Zambia & 2,6 & $2,1-3,0$ & 6 \\
\hline \multirow{9}{*}{121} & Benin & 2,5 & $2,1-2,9$ & 6 \\
\hline & Gambia & 2,5 & $2,3-2,8$ & 6 \\
\hline & Guyana & 2,5 & $2,2-2,6$ & 5 \\
\hline & Honduras & 2,5 & $2,4-2,7$ & 6 \\
\hline & Nepal & 2,5 & $2,3-2,9$ & 5 \\
\hline & Filipinas & 2,5 & $2,3-2,8$ & 9 \\
\hline & Rusia & 2,5 & $2,3-2,7$ & 8 \\
\hline & Ruanda & 2,5 & $2,3-2,6$ & 3 \\
\hline & Suazilandia & 2,5 & $2,2-2,7$ & 3 \\
\hline \multirow{8}{*}{130} & Azerbaiján & 2,4 & $2,2-2,6$ & 7 \\
\hline & Burundi & 2,4 & $2,2-2,6$ & 5 \\
\hline & República Centroafricana & 2,4 & $2,2-2,5$ & 3 \\
\hline & Etiopía & 2,4 & $2,2-2,6$ & 7 \\
\hline & Indonesia & 2,4 & $2,2-2,6$ & 10 \\
\hline & Papua Nueva Guinea & 2,4 & $2,3-2,6$ & 4 \\
\hline & Togo & 2,4 & $1,9-2,6$ & 3 \\
\hline & Zimbabue & 2,4 & $2,0-2,8$ & 7 \\
\hline \multirow{4}{*}{138} & Camerún & 2,3 & $2,1-2,5$ & 7 \\
\hline & Ecuador & 2,3 & $2,2-2,5$ & 5 \\
\hline & Níger & 2,3 & $2,1-2,6$ & 5 \\
\hline & Venezuela & 2,3 & $2,2-2,4$ & 7 \\
\hline \multirow{9}{*}{142} & Angola & 2,2 & $1,9-2,4$ & 5 \\
\hline & República del Congo & 2,2 & $2,2-2,3$ & 4 \\
\hline & Kenia & 2,2 & $2,0-2,4$ & 7 \\
\hline & Kirguistán & 2,2 & $2,0-2,6$ & 6 \\
\hline & Nigeria & 2,2 & $2,0-2,3$ & 7 \\
\hline & Pakistán & 2,2 & $2,0-2,4$ & 6 \\
\hline & Sierra Leona & 2,2 & $2,2-2,3$ & 3 \\
\hline & Tayikistán & 2,2 & $2,0-2,4$ & 6 \\
\hline & Turkmenistán & 2,2 & $1,9-2,5$ & 4 \\
\hline \multirow{5}{*}{151} & Bielorrusia & 2,1 & $1,9-2,2$ & 4 \\
\hline & Camboya & 2,1 & $1,9-2,4$ & 6 \\
\hline & Costa de Marfil & 2,1 & $2,0-2,2$ & 4 \\
\hline & Guinea Ecuatorial & 2,1 & $1,7-2,2$ & 3 \\
\hline & Uzbekistán & 2,1 & $1,8-2,2$ & 5 \\
\hline \multirow{4}{*}{156} & Bangladesh & 2,0 & $1,7-2,2$ & 6 \\
\hline & Chad & 2,0 & $1,8-2,3$ & 6 \\
\hline & República Democrática del Congo & 2,0 & $1,8-2,2$ & 4 \\
\hline & Sudán & 2,0 & $1,8-2,2$ & 4 \\
\hline \multirow{3}{*}{160} & Guinea & 1,9 & $1,7-2,1$ & 3 \\
\hline & Irak & 1,9 & $1,6-2,1$ & 3 \\
\hline & Myanmar & 1,9 & $1,8-2,3$ & 3 \\
\hline 163 & Haití & 1,8 & $\begin{array}{lll}1,7 & 1,8 \\
\end{array}$ & 3 \\
\hline
\end{tabular}


Ł corrupción, al ser un fenómeno que afecta a toda la sociedad, involucra a toda su estructura fundamental.

Dentro de los efectos que puede producir la corrupción en el ámbito social yb político, se encuentra un aumento de la desconfianza que posee la ciudadanía en lo referente a sus representantes, lo que afecta a las instituciones encargadas de impartir justicia, garantizar la seguridad ciudadana y el control de la administración pb́lica. (Øluaga, 1996 en Grcía y otros, 1999). Debido a lo anterior, se produce un alejamiento entre el ciudadano y las instituciones; este alejamiento de la sociedad frente al Estado hace de la corrupción un proceso rápido ya que en la medida que se afianza se hace más difícil restablecer una relación de confianza (Pacheco, 1996, en frcía y otros, 1999).

befecto importante de la corrupción es el costo económico que genera en un país, expresada en la pérdida de recursos, lo que trae como consecuencia que los bienes pb̆licos no se encuentren al servicio de los más necesitados. Junto a esto, la acción de los funcionarios pb́licos corruptos puede hacer que la energía de los empresarios se desvíe desde las actividades productivas hacia la briqueda de Rnta. Ł corrupción está asociada a un mayor déficit fiscal con el consecuente impacto sobre las políticas de estabilización de un país (Informe Comisión Nacional de fíca Pb̆lica, 1994).

Como quiera que el hombre es protagonista, es él quien puede asumir las medidas correctivas o continuar envuelto en la corrupción, por ello pensamos que las personas asumen sus responsabilidades y éstas responden en gran medida a las atribuciones contenidas en las disposiciones psicológicas (Vicuã L et al., 2004).

En suma la transgresión de normas, conseguir para uno o para el entorno próximo beneficios personales, y en alguna medida estas transgresiones son más o menos aceptadas, pueden llevar consigo un trastorno motivacional, entendido como la motivación que lleva a la persona a satisfacer necesidades de probable riesgo o dañ contra la salud personal o el bienestar y con impacto en el entorno inmediato. De esta manera, el proceso motivacional primario que es energético para la acción y que naturalmente está destinado a preservar a la especie, en cambio la motivación secundaria o aprendida desviada en el sentido en que la hemos definido, estará presente en otros tipos de trastornos, donde el impulso para alcanzar metas no saludables para uno o para los demás está vinculado con la autodestrucción y, por ende, con impactos negativos a la sociedad; en este grupo podemos clasificar a los consumidores de sustancias así como a los corruptos, por ello vale la pena iniciar una línea de investigación, teniendo como eje principal la motivación y eje transversal la corrupción.

En el presente estudio queremos despejar la forma cómo los estudiantes universitarios definen a la corrupción, cómo la clasifican, y las medidas remediales que asumirían, en función a la Facultad Académica a la que pertenecen, al ciclo académico y sexo.

Desde este punto de vista, asumimos que el acto corrupto observable a traves de la transgresión de las normas para conseguir provecho personal o de grupo, cuyas clases pueden incluso llegar a la justificación al estilo de creencias irracionales, tales como:No importa si roba, si hace obray Algunas autoridades ganan tan poco que si no fuera por la coima no podrían subsistir» Me pagan tan poco que es justo que me lleve estos materiales, que si los dejo otros(as) se lo llevarán importante es aprobar el curso, a fin de cuentas los contenidos no son necesarios para lo que quiero hacer profesionalmente so importa 
sacrificar a terceros, si de esa forma perjudicamos o mejor arruinamos al enemigo»o $\mathbf{L}$ forma de consolidarnos es distribuyendo el poder entre nuestros incondicionales» estas expresiones encierran motivaciones dentro de personalidades que en las instituciones se constituyen en redes de complicidades más o menos delictivas; ante esta situación, el observador natural, por su interacción directa dentro de una institución educativa, son todos. hbs actún como acusadores y otros como defensores del sistema, ello es lo que importa; en esta investigación hemos indagado la forma cómo definen los estudiantes a la corrupción, cómo la clasifican y si estas percepciones y categorizaciones están vinculadas al género y a la profesión a la que estudian, puesto que es posible que ciertas profesiones tengan mayor proclividad a justificar la corrupción, asociada en gran medida al rol que asumen con las personas e instituciones, y el tipo de casuísticas, de modo que sustentamos las siguientes hipótesis:

$\mathrm{H}_{1} \quad$ Łdefinición de corrupción, la clasificación y el planteamiento remedial difiere en función al sexo en estudiantes universitarios.

$\mathrm{H}_{2} \quad$ Łdefinición de corrupción, la clasificación y el planteamiento remedial difiere en función al ciclo académico al que pertenece el estudiantes universitarios

$\mathrm{H}_{3}$ Łdefinición de corrupción, la clasificación y el planteamiento remedial difiere en función a la Facultad Académica a la que pertenece el estudiante universitario.

\section{MÉTODOS}

El presente estudio es descriptivoeomparativo con un diseñ transversal (Łłnández R B Fernández, C.; Rptista, P., 1997), en cuanto se han seleccionado muestras en función al ciclo académico teniendo en cuenta a las Facultades como conglomerados. El tamañ muestral fue de 931, representativa al 0,03 de margen de error, distribuidos por Facultades y dentro de ellas por Escuelas Académico Profesionales.

bs instrumentos elegidos fueron un cuestionario tipo ensayo, constituido por tres preguntas que a continuación se reproducen:

1. Desde su punto de vista, o como usted lo entiende, defina a la corrupción.

2. Segú su definición, enumere las clases o tipos de corrupción que usted cree o se ha enterado que ocurren en su entorno social próximo, en su facultad.

3. Díganos cómo cree usted que podría solucionarse la corrupción en su ambiente social próximo.

as preguntas fueron validadas por criterio de jueces, tanto para verificar la dirección del contenido como la estructura semántica, la confiabilidad fue por el método del test retes con una muestra de 50 universitarios sin importar el ciclo, facultad académica ni el sexo, a quienes se les examinó en dos oportunidades con un intervalo de 60 días, luego se analizó la concordancia encontrando el coeficiente de 0,98 , dejando entrever que los ítemes utilizados tienen muy bajo error de medición.

Łmuestra seleccionada aleatoriamente contestó de manera libre a un cuestionario de tres preguntas, previamente validadas semánticamente, con una muestra de 50 estudiantes donde importa la forma gramatical en que ellos formulan la pregunta para decodificarla dentro 
del propósito esperado, nos aseguramos que la estructura semántica tenga el 100\% de validez, luego en grupos no mayores de cuatro estudiantes se conversó acerca de sus respuestas con el objeto de conocer la confiabilidad de las mismas, encontramos concordancia entre las opiniones profundizadas en la sesión dinámica con sus respuestas escritas en el cuestionario.

El segundo instrumento fueron sesiones dinámicas, en las que la discusión estuvo centrada en el grupo hacia un tema específico. En el presente estudio, el tema específico fue cada uno de los ítemes; teniendo en cuenta el siguiente procedimiento:

1. bcalizar la idea central en relación a la pregunta.

2. Con la idea central se analizaba el significado.

3. El significado era analizado en bŕqueda del impulso al que obedecen.

4. El producto era evaluado como parte o no de la personalidad.

5. Con cualquiera de los puntos de vista, se discutía en la forma cómo se constituyen, cómo se origina.

6. Analizada la constitución y origen, se discutía acerca de cómo se inicia o empieza el acto corrupto y la forma cómo operan.

7. Visto la forma de inicio y cómo operan, se discutía la razón de cómo se mantiene y la forma cómo podría remediarse.

\section{RESULTADOS}

\section{Conceptualización de corrupción}

Suele suceder en el proceso de la comunicación que el mensaje del emisor termine interpretado por el receptor de manera muy diferente a la intención del primero, esto, sin lugar a duda, porque ambos interlocutores están manejando significados diferentes para las mismas palabras referentes a conceptos, que se prestan a diferentes puntos de vista, entre estos conceptos tenemos el de corrupción.

Para averiguar cómo se conceptualiza a la corrupción, preguntamos a la muestra examinada: Łómo define usted a la corrupción? Duvimos diez contenidos centrales, una categoría de respuestas imprecisas en el sentido que no cierran la idea sino solo la califican, sin llegar a decir lo que es, comparten el 3,2\%, y también hubo el 1,7\% de estudiantes que no conceptán.

En el total de examinados, encontramos diez posibles formas de interpretar a la corrupción, siendo el concepto más compartido el que dice que se trata de conductas de las personas que aprovechándose de su situación sacan beneficios personales» este concepto corresponde al 36,7\% como se podrá observar, dos tercios comparten otros conceptos tales como que es un delito que cometen las personas que ocupan un cargo» en este caso el significado atribuido es el de falta contra la ley. Đo grupo de estudiantes consideran a la corrupción вomo una forma de abuso del poder, conferido» en torno a este concepto encierran el conjunto de falsedades y complicidades que las personas realizan a fin de acceder al poder, piensan que el que asume un cargo ya lleva un caudal de requerimientos que dejan discurrir, 
sin importarles la magnitud del dañ que van dejando. Đo porcentaje de examinados consideran que ła corrupción es una enfermedad, como el cáncer que recorre a la sociedad carcomiéndola desde sus bases» en esta concepción, el corrupto es un enfermo desahuciado, con quien casi nada se puede hacer.

Para otro sector de la muestra la corrupción está asociada con la trasgresión a las normas institucionales, no la consideran como delito, pero sí como falta al cumplimiento del deber, de la función laboral, como aquellos funcionarios que vegetan en sus cargos cobrando sin cumplir con sus funciones.

Para otros la corrupción es la falta de moral, es propia de las personas que no practican los valores morales, y por ello son capaces de actuar tratando a las personas como cosas.

En un porcentaje similar, cercano al 5 hay quienes entienden que la corrupción es un problema social, en cuanto su conducta resulta contradictoria con lo que dicen, no son previsibles, dificultando que las personas o las organizaciones puedan desarrollarse, porque dejan una estela de desconfianza»

Para el 3\% de la muestra, ła corrupción es la ineficacia de la gestión, debido a que los cargos no son ganados por las personas capaces sino por prebendas o como pagos a favores políticos.

bs resultados pueden verse en la Tabla 1, donde la columna bajo la designación de Ji cuadrado indica estos valores, calculados a partir de los porcentajes, todos significativos aun para el 0,01 de margen de error.

Tabla 1. Porcentual y de valores Ji cuadrado de las formas de conceptualizar la corrupción en la muestra total.

\begin{tabular}{lcccc}
\hline \multicolumn{1}{c}{ Concepto } & $\begin{array}{c}\text { Frecuencia } \\
\text { total }\end{array}$ & $\begin{array}{c}\text { \% que } \\
\text { Conceptúan }\end{array}$ & $\begin{array}{c}\text { \% que } \\
\text { Conceptúan }\end{array}$ & $\begin{array}{c}\text { Ji } \\
\text { Cuadrado }\end{array}$ \\
\hline Trasgresión de normas (1) & 73 & 7.8 & 92.2 & $70.9^{* *}$ \\
Abuso de autoridad (2) & 105 & 11.3 & 88.7 & $59.8^{* * *}$ \\
Delito (3) & 139 & 14.9 & 85.1 & $49.0^{* *}$ \\
Enfermedad (4) & 81 & 8.7 & 91.3 & $68.0^{* *}$ \\
Beneficio personal (5) & 342 & 36.7 & 63.3 & $6.8^{* *}$ \\
Problema social (6) & 44 & 4.7 & 95.3 & $81.8^{* *}$ \\
Daño al Perú (7) & 9 & 1.0 & 99.0 & $96.0^{* *}$ \\
Falta de moral (8) & 44 & 4.7 & 95.3 & $81.8^{* *}$ \\
No conceptúan (9) & 16 & 1.7 & 98.3 & $93.0^{* *}$ \\
Problema socialmente aceptado (10) & 20 & 2.1 & 97.9 & $91.4^{* *}$ \\
No precisa (11) & 30 & 3.2 & 96.8 & $87.3^{* *}$ \\
Ineficacia, gestión deficiente (12) & 28 & 3.0 & 97.0 & $88.1^{* *}$ \\
\hline \multicolumn{1}{c}{ Sub totales } & $\mathbf{9 3 1}$ & $\mathbf{1 0 0}$ & & \\
\hline
\end{tabular}

$(* *) \mathrm{P}<0,01$

De la tabla se desprende que hay 10 formas de conceptualizar la corrupción en los estudiantes universitarios, cuya dispersión presenta a un grupo humano con alta heterogeneidad respecto al concepto de la corrupción. Como se puede ver, los porcentajes son altos en la 
conceptualización diferente y los valores Ji cuadrado significativos para el 0,01 y menos ań de margen de error, por lo que afirmamos que el concepto de corrupción no es úico si no disperso enfatizando en diferentes componentes por tanto la posibilidad de comunicarnos con una misma idea cuando hablamos de este problema humano el riesgo de estar entendiendo de manera diferente es significativo.

\section{Conceptualización de corrupción en función al sexo}

Con el propósito de conocer el papel del sexo en las formas de conceptualizar, hemos calculado los porcentajes para varones y para la muestra de mujeres, luego, mediante la razón crítica de diferencia de porcentaje, la hemos contrastado.

Como se puede leer en la Tabla 2 en función al sexo tampoco hemos encontrado predominio significativo en el porcentaje de examinados que compartan de manera similar la definición de corrupción.

$\mathrm{Al}$ analizar las contrastaciones, encontramos que las mujeres casi en el $10 \%$ definen a la corrupción como una trasgresión a la norma frente a $6 \%$ de los varones, donde la diferencia es significativa, sin embargo como se ve sólo llegan hasta el 10\%, esto significa que en un 90\% no comparten esta definición, confirmando lo hallado anteriormente, que la heterogeneidad es la que prima.

bdato que hemos encontrado que resulta conveniente destacar es referente al $3 \%$ de mujeres que no conceptán por sólo el $1 \%$ de varones cuya diferencia es significativa; en este caso, podemos afirmar que son los varones quienes en un $99 \%$ darán alguna de las diez definiciones, en tanto que las mujeres un 97\% también dará alguna de las definiciones encontradas.

En suma tanto varones como mujeres presentan heterogeneidad, oscilando entre diez posibles respuestas sin predominancia significativa de alguna de ellas, tal como puede verse en la tabla 2 .

Tabla 2. De porcentaje y razones críticas de la forma de conceptualizar la corrupción, en la muestra de varones y de mujeres.

\begin{tabular}{cccccccc}
\hline \multirow{2}{*}{ Concepto } & $\begin{array}{c}\text { Fombres } \\
\text { Frencia } \\
\text { total }\end{array}$ & Porcentaje & $\begin{array}{c}\text { Mujeres } \\
\text { Frecuencia } \\
\text { total }\end{array}$ & $\begin{array}{c}\text { Porcentaje } \\
\text { Diferencia }\end{array}$ & $\begin{array}{c}\text { Error } \\
\text { Estándar }\end{array}$ & R.C. \\
\hline 1 & 28 & 5.9 & 45 & 9.9 & -4.0 & 1.77 & $2.27 *$ \\
2 & 59 & 12.4 & 46 & 10.1 & 2.3 & 2.07 & 1.10 \\
3 & 80 & 16.8 & 59 & 13.0 & 3.8 & 2.33 & 1.65 \\
4 & 42 & 8.8 & 39 & 8.6 & 0.3 & 1.85 & 0.14 \\
5 & 174 & 36.6 & 168 & 36.9 & -0.4 & 3.16 & 0.12 \\
6 & 22 & 4.6 & 22 & 4.8 & -0.2 & 1.39 & 0.15 \\
7 & 2 & 0.4 & 7 & 1.5 & -1.1 & 0.65 & 1.72 \\
8 & 21 & 4.4 & 23 & 5.1 & -0.6 & 1.39 & 0.46 \\
9 & 4 & 0.8 & 12 & 2.6 & -1.8 & 0.86 & $2.09 *$ \\
10 & 14 & 2.9 & 6 & 1.3 & 1.6 & 0.94 & 1.72 \\
11 & 13 & 2.7 & 17 & 3.7 & -1.0 & 1.16 & 0.87 \\
12 & 17 & 3.6 & 11 & 2.4 & 1.2 & 1.11 & 1.04 \\
\hline Subtotales & 476 & 100 & 455 & 100 & & & \\
\hline
\end{tabular}

(*) $\mathrm{P}<0.05$

Nota:los núneros debajo de la columna Concepto nominan a la definición de corrupción que se reproduce en la Tabla 1. 


\section{Conceptualización de corrupción en función a la facultad académica}

A continuación, con una metodología similar a la anterior, hemos analizado los conceptos de los estudiantes pertenecientes a cada una de las facultades, encontrando diez (10) formas diferentes de conceptualizar la corrupción.

A partir de las diez formas de definir halladas, hemos creído necesario ubicar a las facultades más homogéneas, es decir, aquellas que se agrupan alrededor del menor núero de definiciones, localizando a las siguientes facultades:1, 2, 4, 17, 19, 21 y 22; en tanto que las facultades que ocupan una dispersión intermedia, esto es por encima de 6 hasta 8 , se encuentran las facultades $5,6,7,11,13,15,16,18,20$ y 23 ; finalmente, las facultades con mayor dispersión son aquellas que se encuentran comprendidos entre el $90 \%$ y el $100 \%$ de definiciones y corresponde a las facultades 3, 8, 9, 10, 12 y 14 .

Es conveniente destacar que ninguna facultad se ha agrupado entre una a tres definiciones, confirmando lo que afirmáramos líneas arriba, la disposición para entender de manera diferente a la corrupción.

Ł imprecisión y la ausencia de conceptualización en la muestra total ha sido 3\% y 2\% respectivamente; sin embargo, la Facultad de Psicología llega al 25\% del total de participantes que se abstienen de conceptualizar; el mayor núero de definiciones imprecisas corresponde a la Facultad de etras y Ciencias que llegan hasta el $11 \%$ de respuestas, tales como son actos malos, actos mal vistos por los demás, actos indeseables, y otras parecidas, donde califican mas no dicen lo que es corrupción.

Finalmente al contrastar el porcentaje de dispersión de cada facultad con el porcentaje total hemos encontrado que las facultades con menor dispersión a un riesgo de error del 0.05 son las facultades $1,5,6,13,15,16,17,20,21$ y 22; y las más homogéneas ań son las facultades 2, 4, y 19; y la facultad más heterogénea ha sido la facultad 9. Estos resultados pueden verse en la Tabla 3 y gráfica 1 .

Como nota importante y a manera de leyenda, en la siguiente tabla sin núero, reproducimos la facultad con el numeral que la identifica, cabe destacar que no corresponde al código formal por razón de tratarse de estudio de casos cuya identificación se prefiere mantener en reserva.

\begin{tabular}{llll}
\hline \multicolumn{1}{c}{ Facultad } & Numeral & \multicolumn{1}{c}{ Facultad } & Numeral \\
\hline Minas & $\mathbf{1}$ & Economía & $\mathbf{1 3}$ \\
Geología - Metalurgia & $\mathbf{2}$ & Sociales & $\mathbf{1 4}$ \\
Psicología & $\mathbf{3}$ & Química & $\mathbf{1 5}$ \\
Enfermería & $\mathbf{4}$ & Odontología & $\mathbf{1 6}$ \\
Fluidos & $\mathbf{5}$ & Contabilidad & $\mathbf{1 7}$ \\
Física & $\mathbf{6}$ & Educación & $\mathbf{1 8}$ \\
Turismo & $\mathbf{7}$ & Medicina & $\mathbf{1 9}$ \\
Administración & $\mathbf{8}$ & Matemática & $\mathbf{2 0}$ \\
Industrial & $\mathbf{9}$ & Ing. Geografía & $\mathbf{2 1}$ \\
Biología & $\mathbf{1 0}$ & Sistemas & $\mathbf{2 2}$ \\
Letras & $\mathbf{1 1}$ & Electrónica & $\mathbf{2 3}$ \\
Derecho & $\mathbf{1 2}$ & & \\
\hline
\end{tabular}


Tabla 3. De porcentaje y razones críticas de la forma de conceptualizar la corrupción, en la muestra segú $F$

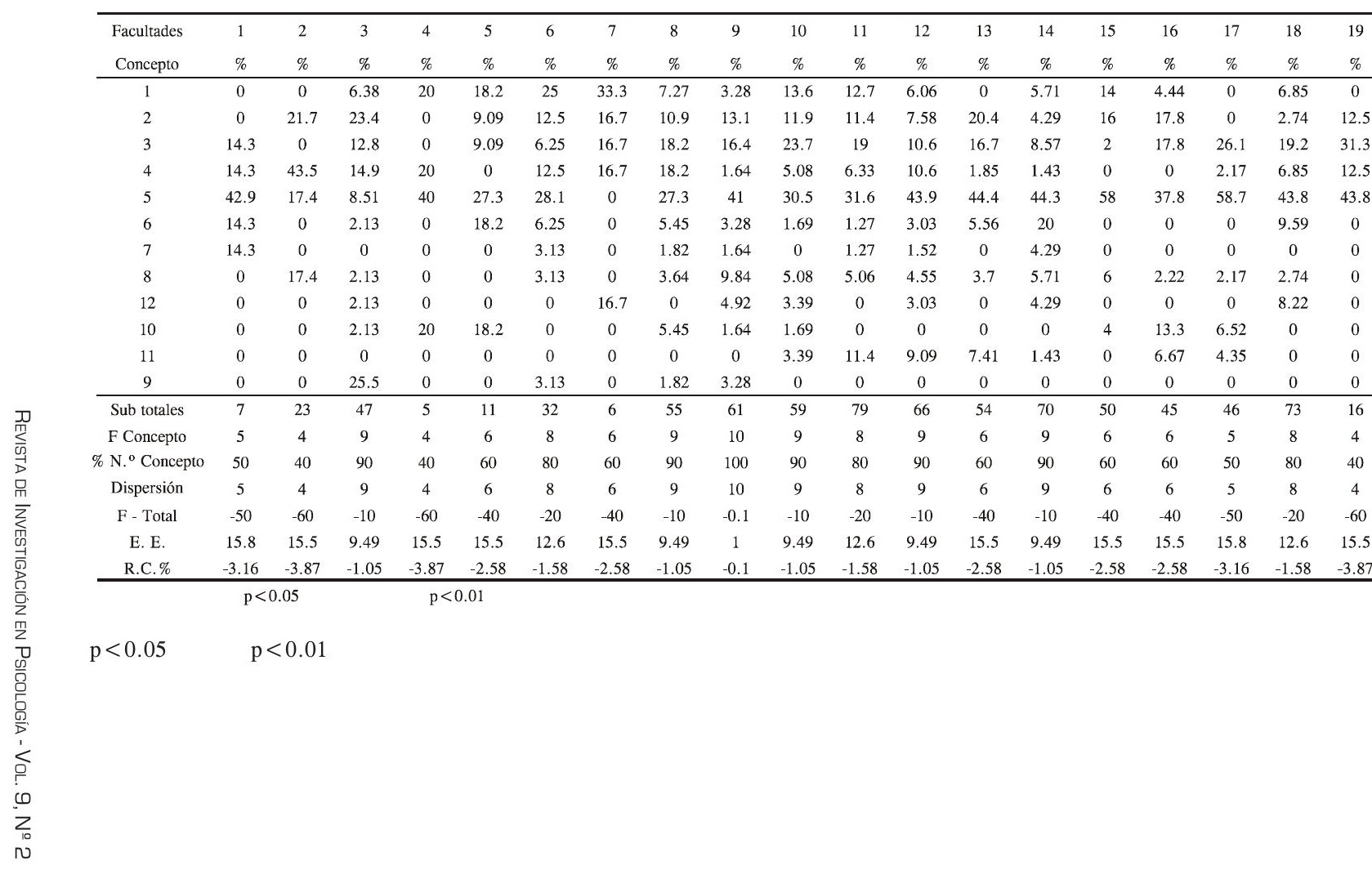


Figura. Dispersión de la conceptualización de corrupción en función a las faculta académicas en estudiantes universitarios.

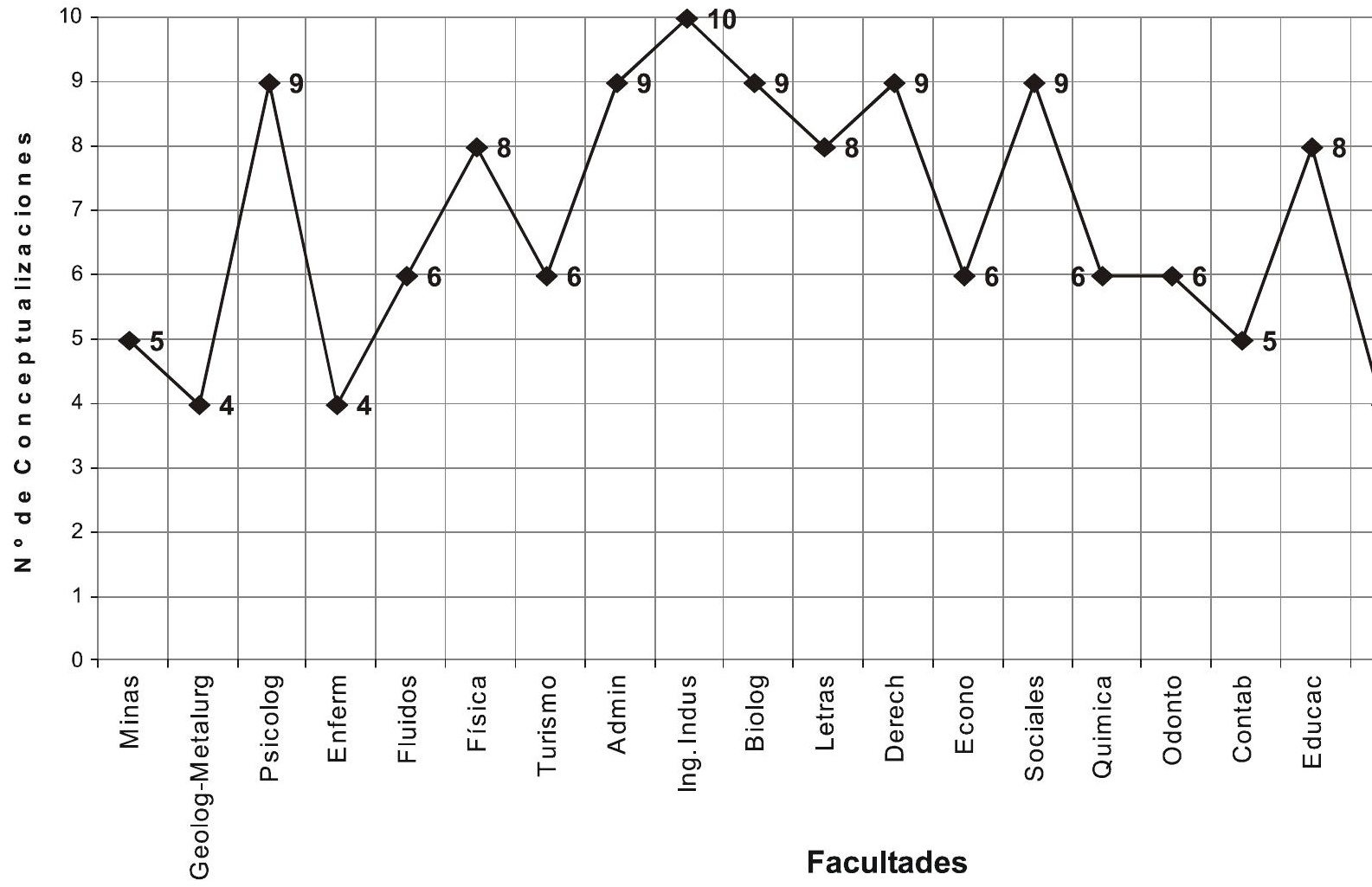




\section{Identificación de tipos de corrupción}

Un tema importante de análisis cuando se estudian problemas sociales radica en ubicar o identificar el rótulo, la denominación la membresía o el tipo que se le asigna al factor o fenómeno observado, que en el presente estudio es la corrupción.

Para ello solicitamos a los encuestados que, según la definición que dieron de la corrupción, enumeren las clases o tipos de corrupción que creían o que se habían enterado que ocurren en su próximo entorno, específicamente su facultad académica. Hemos encontrado 18 tipos o categorías en la muestra total y porcentualizado, con el propósito de calcular el Ji cuadrado para cada uno de los tipos, encontrando que los valores hallados son significativos para más del 0,01 de margen de error en dirección al porcentaje que no comparten con el tipo de corrupción identificado.

Este dato deja entrever la heterogeneidad en la identificación de los tipos de corrupción y con ello la posibilidad que los estudiantes perciben su entorno, escuchan comentarios, ven algunos comportamientos y, a partir de ello, elaboran sus conclusiones; que en el presente se traducen como tipos de corrupción, dejando duda que los tipos identificados correspondan a hechos consumados y que probablemente queden en el comentario, dato que corroboramos cuando, en discusiones de dinámicas de grupo, los participantes señalaban haberse enterado, pero cuyas fuentes eran otros compañeros o también trabajadores y, en algunos casos, docentes, pero que la información recibida era siempre circular, es decir «Me han contado que..., no me consta pero mi informante es de confiar» (véase Tabla 4).

Tabla $N^{0}$ 4. Porcentual y de valores Ji cuadrado de los Tipos de corrupción identificados en el entorno próximo en la muestra total.

\begin{tabular}{lcccc}
\hline \multicolumn{1}{c}{ Tipos } & F tot & $\begin{array}{c}\text { \% que } \\
\text { identifica el } \\
\text { tipo }\end{array}$ & $\begin{array}{c}\text { \% que NO } \\
\text { identifica } \\
\text { el tipo }\end{array}$ & Ji Cuadrado \\
\hline Profesores que cobran por notas (1) & 29 & 1.86 & 98.14 & $92.5^{* *}$ \\
Alumnos que pagan, coimas, sobornos(2) & 141 & 9.05 & 90.95 & $66.9^{* *}$ \\
Malversación, enriquecimiento ilícito (3) & 147 & 9.44 & 90.56 & $65.6^{* *}$ \\
Abuso de poder, burocracia (4) & 512 & 32.86 & 67.14 & $11.5^{* *}$ \\
No Precisa (5) & 106 & 6.80 & 93.20 & $74.4^{* *}$ \\
Plagio (6) & 8 & 0.51 & 99.49 & $97.8^{* *}$ \\
Encubrimiento, Complicidad (7) & 6 & 0.39 & 99.61 & $98.3^{* *}$ \\
Nepotismo (8) & 66 & 4.24 & 95.76 & $83.6^{* *}$ \\
Falsificación (9) & 14 & 0.90 & 99.10 & $96.2^{* *}$ \\
Extorsión, Chantaje (10) & 18 & 1.16 & 98.84 & $95.2^{* *}$ \\
Robo, Peculado (11) & 44 & 2.82 & 97.18 & $88.8^{* *}$ \\
Abuso de poder del docente (12) & 121 & 7.77 & 92.23 & $71.1 * *$ \\
Abuso de poder del alumno (13) & 61 & 3.92 & 96.08 & $84.8^{* *}$ \\
Abuso de poder Gremial, C.F. (14) & 63 & 4.04 & 95.96 & $84.3^{* *}$ \\
Abuso de poder Gremial Tercio Est (15) & 71 & 4.56 & 95.44 & $82.4^{* *}$ \\
Abuso de poder Gremial Cons Fac y Uni (16) & 8 & 0.51 & 99.49 & $97.8^{* *}$ \\
Favoritismo docentes, alumnos, gremial (17) & 77 & 4.94 & 95.06 & $81.0^{* *}$ \\
Fraude Electoral (18) & 33 & 2.12 & 97.88 & $91.5^{* *}$ \\
No se ha Enterado (19) & 26 & 1.67 & 98.33 & $93.2^{* *}$ \\
Suplantación de Estudiantes (20) & 7 & 0.45 & 99.55 & $98.0^{* *}$ \\
\hline \multicolumn{1}{c}{ Total } & $\mathbf{1 5 5 8}$ & $\mathbf{1 0 0}$ & & \\
\hline (**) p < 0.01 & & & & \\
& & & & \\
\hline
\end{tabular}




\section{Identificación de los tipos de corrupcion en el entorno próximo en función al sexo}

Para averiguar si el porcentaje que identifican los tipos de corrupción difieren según el sexo, hemos contrastado mediante la razón crítica de diferencia de porcentajes las frecuencias relativas emitidas por hombres y mujeres. De los 18 tipos identificados, difieren en 6 de ellos, dejando entrever que el sexo plantea diferencias en la identificación de los siguientes tipos de corrupción: malversación, donde los varones porcentualmente identifican más que las mujeres, así mismo en robo y peculado, abuso del poder del docente y en suplantaciones de estudiantes para rendir exámenes difíciles.

Las mujeres predominan porcentualmente respecto a los varones para identificar el abuso del poder del tercio estudiantil como también el abuso del poder del consejo de facultad y universitario.

De los datos se desprende que el tipo de corrupción que llega hasta el $34 \%$ corresponde al abuso del poder por parte de la burocracia, es decir en la administración en las diferentes áreas de la universidad.

El porcentaje de estudiantes que no precisan su respuesta, llega hasta el $8 \%$ es decir que dicen que hay dolo o corrupción pero no mencionan el tipo; hasta el 2\% de examinados expresan no haberse enterado, sin lugar a duda es el $98 \%$ de los encuestados que reportan que sí se han enterado dentro de las comunicaciones informales. Estos resultados pueden verse detalladamente en la Tabla 5.

Tabla 5. De porcentaje sobre el total de respuestas emitidas y razones críticas de la identificación en el entorno próximo de los tipos de corrupción, en la muestra de varones y de mujeres.

\begin{tabular}{lccccccc}
\hline \multirow{2}{*}{ Tipos } & $\begin{array}{c}\text { Frecuencia } \\
\text { total }\end{array}$ & Porcentaje & $\begin{array}{c}\text { Frecuencia } \\
\text { total }\end{array}$ & Porcentaje & Diferencia & $\begin{array}{c}\text { Error } \\
\text { Estándar }\end{array}$ & R.C. \\
\hline 1 & 15 & 1.85 & 14 & 1.87 & 0.0 & 0.69 & -0.02 \\
2 & 77 & 9.52 & 64 & 8.54 & 1.0 & 1.45 & 0.67 \\
3 & 93 & 11.50 & 54 & 7.21 & 4.3 & 1.47 & $2.92^{* *}$ \\
4 & 258 & 31.89 & 254 & 33.91 & -2.0 & 2.38 & -0.85 \\
5 & 46 & 5.69 & 60 & 8.01 & -2.3 & 1.28 & -1.81 \\
6 & 5 & 0.62 & 3 & 0.40 & 0.2 & 0.36 & 0.61 \\
7 & 2 & 0.25 & 4 & 0.53 & -0.3 & 0.32 & -0.90 \\
8 & 28 & 3.46 & 38 & 5.07 & -1.6 & 1.03 & -1.57 \\
9 & 10 & 1.24 & 4 & 0.53 & 0.7 & 0.47 & 1.49 \\
10 & 11 & 1.36 & 7 & 0.93 & 0.4 & 0.54 & 0.79 \\
11 & 31 & 3.83 & 13 & 1.74 & 2.1 & 0.83 & $2.54 * *$ \\
12 & 75 & 9.27 & 46 & 6.14 & 3.1 & 1.35 & $2.33^{* *}$ \\
13 & 31 & 3.83 & 30 & 4.01 & -0.2 & 0.98 & -0.18 \\
14 & 27 & 3.34 & 36 & 4.81 & -1.5 & 1.00 & -1.46 \\
15 & 25 & 3.09 & 46 & 6.14 & -3.1 & 1.07 & $-2.86^{* *}$ \\
16 & 1 & 0.12 & 7 & 0.93 & -0.8 & 0.37 & $-2.18^{* *}$ \\
17 & 45 & 5.56 & 32 & 4.27 & 1.3 & 1.09 & 1.18 \\
18 & 12 & 1.48 & 21 & 2.80 & -1.3 & 0.74 & -1.79 \\
19 & 10 & 1.24 & 16 & 2.14 & -0.9 & 0.66 & -1.37 \\
20 & 7 & 0.87 & 0 & 0 & 0.9 & 0.33 & $2.66^{* *}$ \\
\hline Total & $\mathbf{8 0 9}$ & & $\mathbf{7 4 9}$ & & & & \\
\hline & & & & & & & \\
\hline
\end{tabular}

(**) $\mathrm{p}<0.01$ 
bs numerales debajo de tipos corresponden a las designaciones de la Tabla 6.

Tabla 6. De conversión de numerales al tipo de corrupción identificado por la muestra examinada.

\begin{tabular}{|c|c|c|c|}
\hline Numeral & Tipos & Numeral & Tipos \\
\hline 1 & Profesores que cobran por notas. & 11 & Robo, peculado. \\
\hline 2 & $\begin{array}{l}\text { Alumnos que pagan para } \\
\text { aprobar, coimas, cutras. }\end{array}$ & 12 & $\begin{array}{l}\text { Abuso del poder del docente, no } \\
\text { dicta clases. }\end{array}$ \\
\hline 3 & $\begin{array}{l}\text { Malversación, enriquecimiento } \\
\text { ilícito. }\end{array}$ & 13 & Abuso de poder del alumno. \\
\hline 4 & $\begin{array}{l}\text { Abuso de poder en la burocracia, } \\
\text { tráfico de influencias. }\end{array}$ & 14 & $\begin{array}{l}\text { Abuso de poder gremial, Centro } \\
\text { Federado. }\end{array}$ \\
\hline 5 & No precisan. & 15 & $\begin{array}{l}\text { Abuso de poder del Tercio } \\
\text { Estudiantil. }\end{array}$ \\
\hline 6 & Plagio. & 16 & $\begin{array}{l}\text { Abuso de poder del Consejo Univ. } \\
\text { del Consejo de Facultad. }\end{array}$ \\
\hline 7 & Encubrimiento complicidad. & 17 & Favoritismo. \\
\hline 8 & Nepotismo. & 18 & Fraude electoral. \\
\hline 9 & Falsificación. & 19 & No se ha enterado. \\
\hline 10 & Extorsión, chantaje. & 20 & Suplantación de estudiantes. \\
\hline
\end{tabular}

\section{Identificación de los tipos de corrupción en función a la facultad académica}

Rspecto a la identificación de actos de corrupción, llama la atención que el 98,23\% reportan haberse enterado de algń acto de corrupción y sólo el 93,20\% son precisos al identificar el acto de corrupción. El núnero total de actos de corrupción, tal como lo seãlan los encuestados, suman dieciocho, a partir de ello podemos identificar las facultades que resultan con menos actos de corrupción, de las que resultan con mayor actos de corrupción; las primeras serán las más homogéneas, es decir aquellas que mencionan solo unos pocos actos de corrupción, pudiendo clasificarlas en tres grandes segmentos, facultades homogéneas, tales como 1. Minas, 5. Fluidos, 7. Turismo y 20 Matemáticas; facultades académicas con núnero de corrupción intermedio, es decir entre 5 hasta 14 actos de corrupción identificados, tenemos las siguientes facultades:2. CologíaMetalurgia, 17. Contabilidad, 4. Enfermería, 19. Medicina, 21. Ing. Cográfica, 22. Sistemas, 15. @ímica, 23. Electrónica, 6. Física, 14.-Sociales, 16. Dontología, 8. Administración, 13. Economía, 18. Educación, 12. Derecho, 3. Psicología y 10. Blogía. is facultades muy heterogéneas, es decir con los mayores núneros de actos corruptos, identificados iguales o mayores de 15 tenemos las facultades 9 . Ing. Industrial y 11. Etras y tmanidades; como se confirma con las razones críticas de diferencias de porcentajes que no son significativas, esto quiere decir que el porcentaje actos corruptos identificados no discrepa con el porcentaje del total de actos corruptos de los que han dado cuenta los examinados.

bs actos corruptos ordenados porcentualmente se muestran en la Tabla 7. 
Tabla 7. De ordenamiento porcentual en función al núero de facultades cuyos estudiantes identifican el tipo de corrupción.

\begin{tabular}{clc}
\hline Orden & \multicolumn{1}{c}{ Tipo } & Porcentajes \\
\hline 1 & Abuso del poder en la burocracia & $100 \%$ Las 23 Facultades \\
2 & Abuso del poder del docente & $83 \%$ 19 Facultades \\
3 & Alumnos que pagan a profesor para aprobar & $78 \%$ 18 Facultades \\
3 & Malversación de fondos de la facultad & $78 \%$ 18 Facultades \\
4 & Abuso de poder del Tercio & $74 \%$ 17 Facultades \\
5 & Nepotismo & $61 \%$ 14 Facultades \\
5 & Abuso de poder de alumnos & $61 \%$ 14 Facultades \\
5 & Favorismos en docentes, alumnos y gremio estudiantil & $61 \%$ 14 Facultades \\
\hline
\end{tabular}

bs detalles para cada facultad y el tipo de corrupción pueden leerse en la Tabla 8.

\section{Soluciones para la corrupción en la muestra total}

Conocida la heterogeneidad en la conceptualización de la corrupción, la identificación de los tipos de corrupción en conformidad con la definición dada, es importante conocer las medidas que tomarían para enfrentar este problema, para lo cual les preguntamos:Cómo cree usted que podría solucionarse la corrupción en su ambiente social próximo?

Ethos identificado trece posibles soluciones, ninguna de ellas pasan del $60 \%$, lo que deja entrever que nuevamente nos encontramos ante diversidad de puntos de vista donde la solución de mayor porcentaje apenas alcanza al $18,67 \%$ cercano al $18,54 \%$, correspondientes a eambiar autoridades,y mediante la educación en valores:notamos que el $85 \%$ y el 81 , respectivamente tienen otras opiniones. Como se puede ver, la ausencia de una tendencia marcada de opinión compartida, debilita la fuerza para conseguir la disminución de este problema.

Encontramos que uno de cada doscientos opina que con la privatización de las instituciones del Estado, la corrupción ingresaría en franco retroceso, en las dinámicas grupales en este tema los participantes ingresan en contradicciones, afirman que la burocracia es el nidoxdonde se encuba y desarrolla la corrupción, por tanto eliminando el agente promotor de la burocracia se daría un gran avance; sin embargo, esto en las universidades de gestión estatal llevaría a la privatización, que es el tema donde las contradicciones se agudizan.

El 2\% no precisa su alternativa de solución, por ejemplo dicen:Mediante el cambio» $\checkmark$ iendo las cosas de otra maneray \&iendo diferentes»y otras parecidas.

Para el1\% es un problema que no tiene solución; estos resultados pueden verse en la Tabla 9. 
Tabla 8. De porcentaje y razones críticas de las Identificaciones de los tipos de corrupción, en la muestra segń

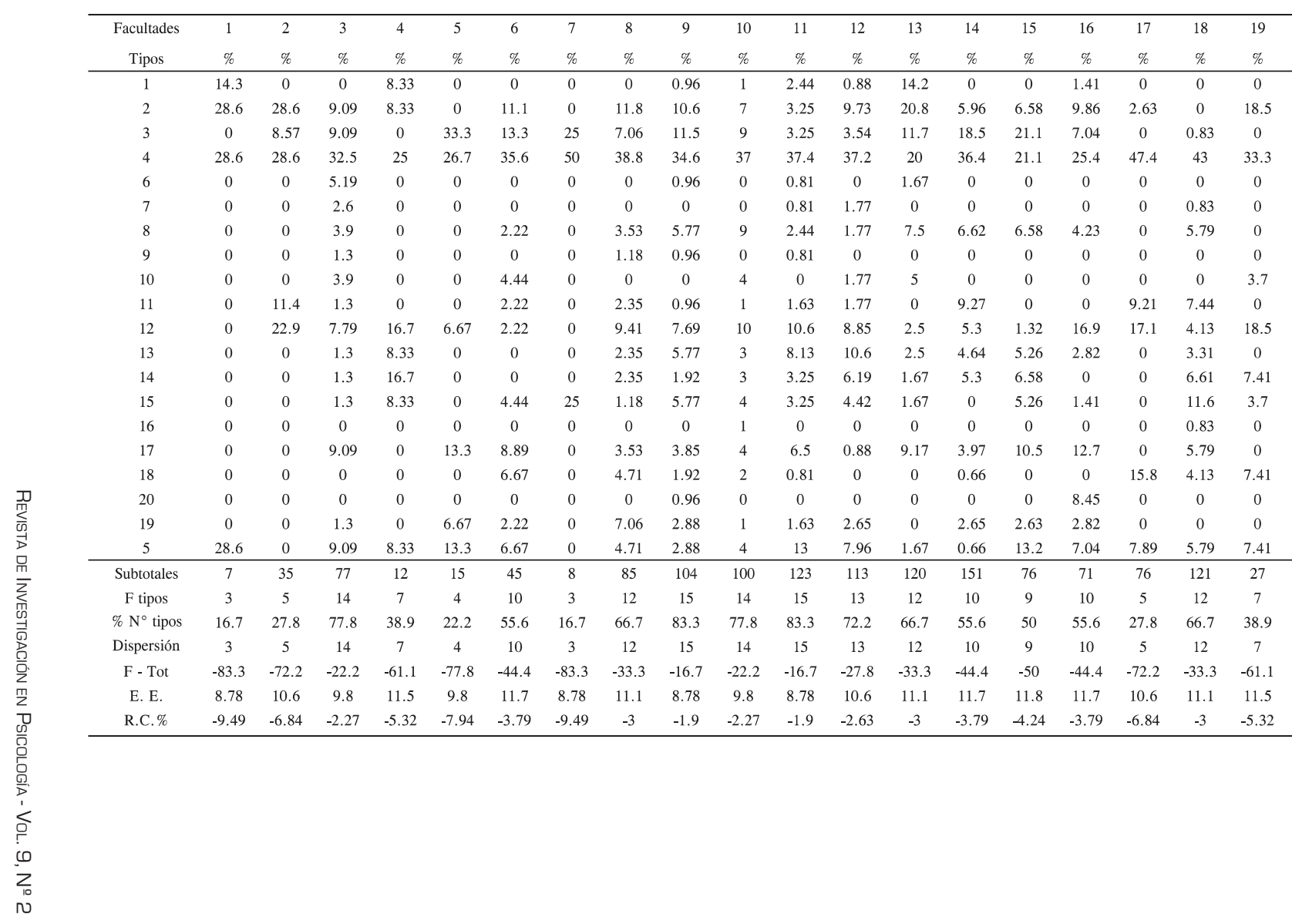


Tabla 9. Porcentual y de valores Ji cuadrado de las medidas que aplicarían a fin de solucionar el problema de la corrupción en la muestra total.

\begin{tabular}{llccc}
\hline \multicolumn{1}{c}{ Soluciones } & F tot & $\begin{array}{c}\text { \% que da } \\
\text { Solución }\end{array}$ & $\begin{array}{c}\text { \% que NO } \\
\text { da Solución }\end{array}$ & Ji Cuadrado \\
\hline Aplicación de medidas restrictivas (1) & 80 & 7.38 & 92.62 & $72.5^{* *}$ \\
Fiscalización (auditorías, investigación) (2) & 137 & 12.64 & 87.36 & $55.6^{* *}$ \\
Transparencia (3) & 87 & 8.03 & 91.97 & $70.3^{* *}$ \\
Mejor trato al docente (4) & 8 & 0.74 & 99.26 & $96.9^{* *}$ \\
Cambio del Sistema (5) & 87 & 8.03 & 91.97 & $70.3^{* *}$ \\
Cambio de Autoridades (6) & 159 & 14.67 & 85.33 & $49.7^{* *}$ \\
Evaluación Docente y Administrativo (7) & 24 & 2.21 & 97.79 & $91.1^{* *}$ \\
Imposible Solución (8) & 14 & 1.29 & 98.71 & $94.7^{* *}$ \\
Educación en Valores (9) & 201 & 18.54 & 81.46 & $39.4^{* *}$ \\
No Precisa (10) & 27 & 2.49 & 97.51 & $90.1^{* *}$ \\
Cambio Individual (11) & 88 & 8.12 & 91.88 & $70.0^{* *}$ \\
Autoridades Probas (12) & 60 & 5.54 & 94.46 & $78.9^{* *}$ \\
Concientizando a la población (13) & 85 & 7.84 & 92.16 & $70.9^{* *}$ \\
Participación de los Estudiantes (14) & 21 & 1.94 & 98.06 & $92.2^{* *}$ \\
Privatizando (15) & 6 & 0.55 & 99.45 & $97.6^{* *}$ \\
\hline Total & 1084 & 100 & & \\
\hline
\end{tabular}

(**) $\mathrm{P}<0.01$

\section{Identificación de las soluciones al problema de la corrupcion en el entorno proximo en función al sexo}

Con el propósito de averiguar el papel que cumple el sexo en el planteamiento de soluciones hacia la corrupción hemos encontrado que solo en cuatro de trece soluciones, es decir en el $30,8 \%$ hay diferencias significativas, los varones consideran que con medidas restrictivas y con el cambio de autoridades se resolverá el problema de la corrupción; por su parte las mujeres consideran que mediante la educación en valores y concientizando a la población se resolverá el problema. Cabe destacar que las diferencias encontradas es por la gran discrepancia dentro de bajos porcentajes, por ejemplo, los varones en el $11 \%$ dicen que con medidas restrictivas se resolverá el problema, mientras que las mujeres piensan igual solo en el $4 \%$.

Como se puede observar, en el $69.2 \%$, no hay discrepancias por género, y siendo los porcentajes menores del $60 \%$, no encontramos predominio sino diversidad, también en este análisis encontramos heterogeneidad o gran dispersión en las iniciativas para enfrentar y resolver el problema de la corrupción, tal como puede verse en la Tabla 10. 
Tabla 10. De porcentaje sobre el total de respuestas emitidas y razones críticas de la idea de solución del problema de corrupción, en la muestra de varones y de mujeres.

\begin{tabular}{|c|c|c|c|c|c|c|c|}
\hline \multirow[b]{2}{*}{ Soluciones } & \multicolumn{2}{|c|}{ Hombres } & \multicolumn{2}{|c|}{ Mujeres } & \multirow[b]{2}{*}{ Diferencia } & \multirow[b]{2}{*}{$\begin{array}{c}\text { Error } \\
\text { Estándar }\end{array}$} & \multirow[b]{2}{*}{ R.C. } \\
\hline & $\begin{array}{c}\text { Frecuencia } \\
\text { total }\end{array}$ & Porcentaje & $\begin{array}{c}\text { Frecuencia } \\
\text { total }\end{array}$ & Porcentaje & & & \\
\hline 1 & 61 & 10.66 & 19 & 3.71 & 7.0 & 1.54 & $4.52 * *$ \\
\hline 2 & 75 & 13.11 & 62 & 12.11 & 1.0 & 2.02 & 0.50 \\
\hline 3 & 50 & 8.74 & 37 & 7.23 & 1.5 & 1.64 & 0.92 \\
\hline 4 & 4 & 0.70 & 4 & 0.78 & -0.1 & 0.52 & -0.16 \\
\hline 5 & 51 & 8.92 & 36 & 7.03 & 1.9 & 1.64 & 1.15 \\
\hline 6 & 97 & 16.96 & 62 & 12.11 & 4.8 & 2.13 & $2.28 * *$ \\
\hline 7 & 10 & 1.75 & 14 & 2.73 & -1.0 & 0.91 & -1.09 \\
\hline 8 & 6 & 1.05 & 8 & 1.56 & -0.5 & 0.69 & -0.74 \\
\hline 9 & 91 & 15.91 & 110 & 21.48 & -5.6 & 2.37 & $-2.35^{* *}$ \\
\hline 10 & 14 & 2.45 & 13 & 2.54 & -0.1 & 0.95 & -0.10 \\
\hline 11 & 44 & 7.69 & 44 & 8.59 & -0.9 & 1.67 & -0.54 \\
\hline 12 & 30 & 5.24 & 30 & 5.86 & -0.6 & 1.40 & -0.44 \\
\hline 13 & 24 & 4.20 & 61 & 11.91 & -7.7 & 1.66 & $-4.65^{* *}$ \\
\hline 14 & 14 & 2.45 & 7 & 1.37 & 1.1 & 0.83 & 1.31 \\
\hline 15 & 1 & 0.17 & 5 & 0.98 & -0.8 & 0.47 & -1.71 \\
\hline Total & 572 & 512 & & & & & \\
\hline
\end{tabular}

$(* *) \mathrm{p}<0.01$

Con el propósito de identificar las propuestas de solución, los numerales del cuadro anterior debajo de la columna soluciones corresponden a los siguientes contenidos:

Tabla 11. De conversión de numerales a las propuestas de solución al problema de corrupción en la muestra examinada.

\begin{tabular}{|c|c|c|c|}
\hline Numeral & Tipos & Numeral & Tipos \\
\hline 1 & Aplicando medidas restrictivas & 9 & Educación en valores \\
\hline 2 & $\begin{array}{l}\text { Fiscalizando, auditorías, investigaciones } \\
\text { y denuncias }\end{array}$ & 10 & No precisa \\
\hline 3 & $\begin{array}{l}\text { Transparencia en los procesos, } \\
\text { electorales y toma de decisiones }\end{array}$ & 11 & $\begin{array}{l}\text { Cambiando individualmente en la forma } \\
\text { de pensar y en la honestidad }\end{array}$ \\
\hline 4 & Mejor trato al Docente & 12 & Eligiendo autoridades \\
\hline 5 & $\begin{array}{l}\text { Cambio del sistema, de ideologías, de } \\
\text { Legislativo y política educativa }\end{array}$ & 13 & $\begin{array}{l}\text { Concientizando a la población, estudiantes } \\
\text { y funcionarios }\end{array}$ \\
\hline 6 & Cambio de autoridades & 14 & Con más participación de los estudiantes \\
\hline 7 & Evaluando a docentes y administrativos & 15 & Privatizando el sector público \\
\hline 8 & Imposible de solucionarse & & \\
\hline
\end{tabular}




\section{Identificación de las soluciones al problema de corrupción en función a la facultad académica}

Para averiguar las soluciones que proponen los estudiantes al problema de la corrupción, hemos tabulado el número de propuestas dadas por cada facultad, calculado el porcentaje y en función a este hemos encontrado que el número máximo de propuestas llegan hasta el $93 \%$, es decir, 13 propuestas de un total de 14 y el mínimo han sido 2 propuestas; como se puede observar, tampoco hay homogeneidad, por el contrario, otra vez aparece la heterogeneidad, que nos permite, a partir del promedio con su desviación estándar identificar tres bloques, las facultades más homogéneas en la propuestas de soluciones, las intermedias y las muy heterogéneas, habiendo encontrado que en la primera categoría de facultades homogéneas sólo hemos localizado a una que corresponde a la facultad de enfermería (4).

En la categoría intermedia, es decir entre 4 hasta 10 propuestas de solución tenemos las facultades: Ing. Geográfica (21), Medicina (19), Contabilidad (17), Turismo (7), Geología Metalurgia (2), Sistemas (22), Matemáticas (20), Minas (1), Economía (13), Electrónica (23), Odontología (16), Química (15), Fluidos (5), Educación (18) y Sociales (14); las facultades muy heterogéneas en proponer soluciones son las siguientes, Ing Industrial (9), Derecho (12), Letras y Humanidades (11), Física (6), Psicología (3), Biología (10), y Administración (8). Estos resultados podemos verlos en la Tabla 12 (véase página 88).

Para identificar las propuestas de solución al problema de corrupción a continuación presentamos una tabla en la que podrá leerse el tipo de solución planteada, el porcentaje y el número de facultades que la proponen, confirmando lo analizado anteriormente, esto es la gran variabilidad en propuestas de solución al problema. 
PERCEPCIÓN, TIPOS Y MEDIDAS DE CONTROL DE LA CORRUPCIÓN

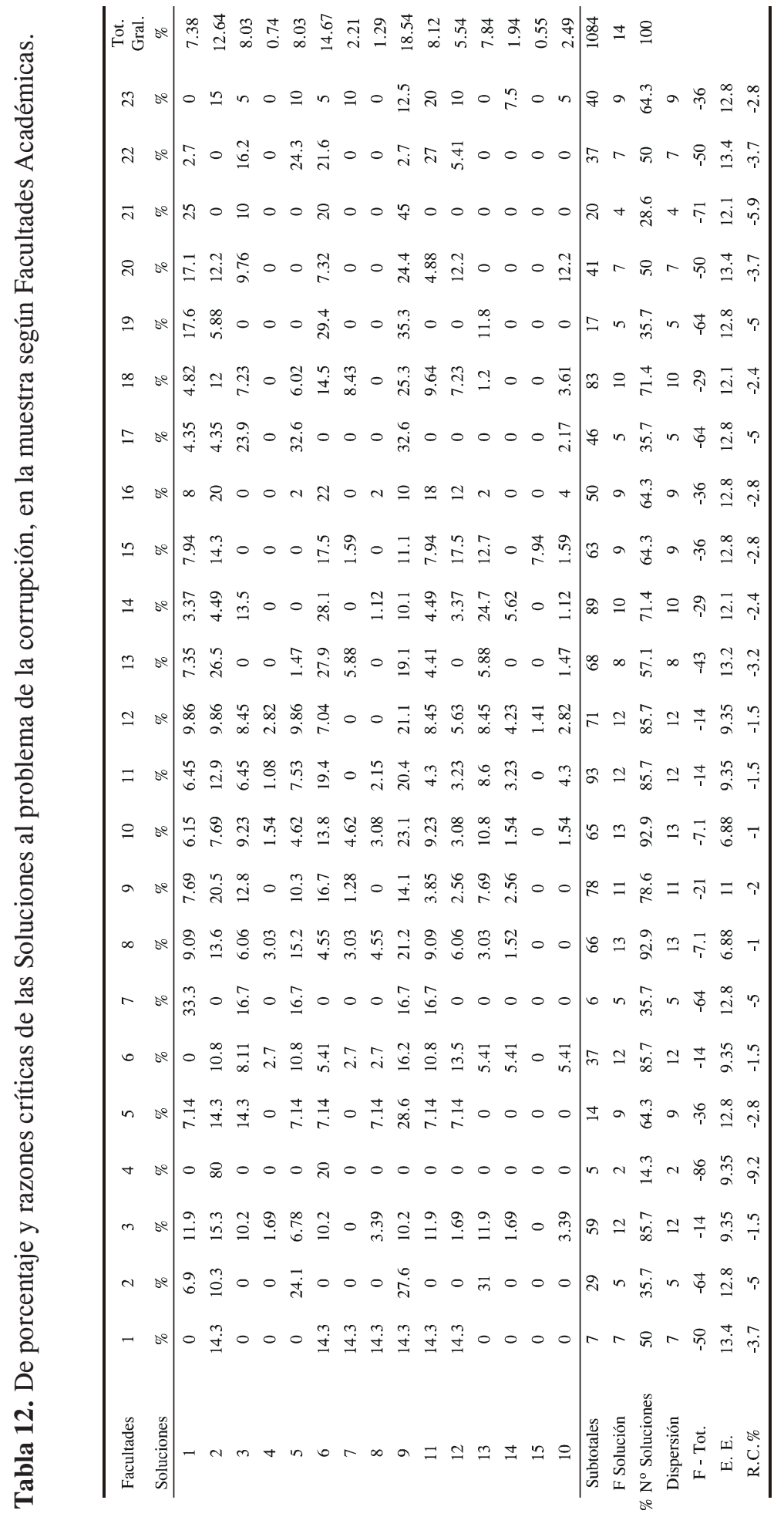


LUIS VICUÑA P. ET AL.

\section{DISCUSIÓN}

Pese a que en los últimos cinco años en nuestro medio se viene hablando de la corrupción en sus diferentes formas, describiéndola, señalando las alternativas que las autoridades de turno proponen, las estrategias que utilizan para detectar al corrupto, nos harían pensar que los medios de comunicación y las opiniones de personas autorizadas debían ejercer influencia para homogenizar el concepto de corrupción, de forma tal que la podamos identificar fácilmente, comunicarnos con transparencia y asumir las medidas pertinentes; sin embargo hemos encontrado que los estudiantes universitarios la conceptúan de diez formas distintas, donde el sexo ni la facultad a la que pertenecen ni el ciclo académico determinan sesgos de opinión lo suficientemente marcados como para afirmar que son variables influyentes.

Cuando preguntamos a los mismos estudiantes si están enterados de actos corruptos en su entorno próximo enfatizando a la facultad académica a la que pertenecen, también encontramos diversidad de tipos de actos corruptos llegando hasta dieciocho, hecho que marca nuevamente dispersión, puesto que dentro de una misma institución con el mismo modelo organizacional y agrupada en facultades académicas encontramos variedades de actos corruptos; este hecho cuando es confrontado en pequeños grupos mediante sesiones dinámicas encontramos que la fuente de la identificación del acto corrupto es el rumor, el comentario de un conocido a quien se le concede credibilidad, sólo en pocos casos y generalmente referentes a lo que están involucrados como es el centro federado y el tercio, las apreciaciones del acto corrupto se centran en afirmaciones personales. Sin embargo, no podemos considerar como falto de confiabilidad las otras identificaciones corruptas, dado que se repiten en frecuencias que si bien no son representativas porque no pasan el $33 \%$ se confirman entre el dato de la encuesta con la expresión verbal en la dinámica de grupos.

En las dinámicas obtuvimos un dato importante, cerca del $20 \%$ de los participantes afirmaba y defendía el punto de vista que la corrupción se presenta con características de estabilidad como un componente de la cultura en las organizaciones burocráticas, principalmente, en las estatales, de allí que resulta difícil controlarla o reducirla o que ésta iría de la mano con la reducción del aparato estatal.

Sin embargo, en las encuestas la privatización sólo figura como una solución con un porcentaje muy bajo, hecho que significa que si este componente fuera un elemento de análisis en trabajos de pequeños grupos como alternativa de solución de la corrupción es probable que del debate se madure la idea del impacto que tendría la reducción del aparato estatal sobre la corrupción, de modo que al parecer dentro de la heterogeneidad de alternativas de solución donde no se visualiza una medida porcentualmente dominante, surge como una posibilidad implícita el abordaje de la privatización como un controlador de la corrupción, de manera similar surge el criterio más o menos uniforme con características de mayor estabilidad para aceptar que la corrupción son actos donde dentro de las organizaciones burocráticas que conceden en algún grado el poder a sus trabajadores estos la utilizan para sacar provecho personal. 


\section{CONCLUSIONES}

1. La conceptualización de la corrupción es heterogénea, los estudiantes proporcionan hasta diez conceptos diferentes sin encontrar diferencias en función al sexo, a la facultad a la que pertenecen ni el ciclo académico.

2. La identificación de actos corruptos ofrece un panorama de dieciocho tipos, donde la baja concentración porcentual en cada uno es un indicador de la diversidad o heterogeneidad, donde el sexo, la facultad a la que pertenece el estudiante ni el ciclo académico plantean diferencias.

3. Las soluciones propuestas por los estudiantes universitarios al problema de la corrupción llegan hasta un total de catorce soluciones con baja concentración porcentual en cada una, lo que indica heterogeneidad o dispersión para tener como idea central un modelo o pocos modelos para solucionar el problema de la corrupción, este resultado es similar en las diferentes facultades académicas, ciclos de estudio y el sexo del estudiante universitario.

4. Se encontrará dificultad significativa para que el mensaje con el tema de la corrupción resulte similarmente entendido por lo menos por el $35 \%$ de la audiencia, porcentaje similar se encontrará para aceptar los actos corruptos dominantes y la solución pertinente al problema de la corrupción.

\section{REFERENCIAS BIBLIOGRÁFICAS}

1. Vicuña, L. (2004). "Disposiciones psicológicas hacia la corrupción en escolares y Universitarios de la Universidad de Lima". Revista de Investigación en Psicología. Vol. $7 \mathrm{~N}^{\circ}$ 1, Julio 2004.

2. Garcia, M Hormazábal, N. Mosalve D,. Rayo C. Riffo, ,Rojas, T. Y Rosales. (1999). El fenómeno de la corrupción desde una perspectiva psicosocial. Seminario para optar el grado de Licenciado en Psicología. Concepción.

3. Fernández y Dols (1993). Norma Perversa: Hipótesis Teórica Psicothema. 5, 91-101. p. 92, España.

4. Hernández,R.;. Fernández, C.; Baptista, P. (1997). Metodología de la Investigación. México: Mc Graw H-Hill.

5. Silva, C y Hernández, M. "Las formas cotidianas de la corrupción: un análisis de discurso". Revista Latinoamericana de Psicología 29: 243-260,

6. Huerta, R. (1992). "Corrupción entre la sociedad y el poder". Visión, 1-15 de agosto.

7. Huntington, S. y Scott, S. (1994). Corrupción: policía y sociedad. Uam-Azcapotzalco. [Documento web] URL http://www.azc.uam.mx/cotidiando68/doc9.html

8. Transparency International (1999). Índice de percepción de corrupción. Transparency International. [Documento web] URL http://www.transparency.org/documents/cpi/ index.es.html 
9. Transparency Internacional (2006). Índice de percepción de corrupción. Transparency International. [Documento web] URL http://www.transparency.org/documents/cpi/ index.es.html

10. Informe de Comisión Nacional de Ética Pública (1994). Ética pública: probidad, transparencia y responsabilidad al servicio de los ciudadanos. Santiago de Chile. 
$+1$ 